\title{
USING E-SURVEYS TO ACCESS THE VIEWS OF FOOTBALL FANS WITHIN ONLINE COMMUNITIES ${ }^{1}$
}

\begin{abstract}
This essay aims to discuss the key benefits and problems involved in using online surveys (e-surveys) for the purpose of accessing the views of football fans that interact with one another via online discussion forums/message boards. Methodological strategies that were adopted and critical issues that arose regarding the dissemination of an e-survey within a specific online community for football fans are reflected upon. Suggestions for researchers adopting similar methodologies to access the views of football fans are provided and it is argued that an ethnographic approach needs to be adopted by researchers who aim to maximise the quality and quantity of e-survey responses. In particular, the importance of planning the researchers' entrée into the community under study - involving the establishment and maintenance of rapport with key gatekeepers - is considered essential for the success of future studies.
\end{abstract}

\section{Introduction}

Potential research opportunities created by the rapid expansion of Internet access were noted at the end of the 1990s. At this time the global number of Internet users was around 50 million. ${ }^{2}$ Now, with the number of people online surpassing 1.5 billion and increasing rapidly year-by-year, the Internet's value for conducting research is ever more apparent. Although the demographic of Internet users is still not wholly representative of any given country's population, ${ }^{3}$ it is, nonetheless, more representative than ever before and grants the researcher access to a far greater volume and variety of source material than most traditional avenues of research. ${ }^{4}$ 
As a result of this, Hine states that since the late 1990s there has been a rapid expansion of academic literature discussing CMC (Computer Mediated Communication) as a research tool within the social sciences. ${ }^{5}$ As an example Hine refers to a website housing a huge bibliography of some 1032 published articles and conference presentations up to the end of 2002 dedicated to web survey methodology. ${ }^{6}$ On recent inspection (in August 2011), the website referred to by Hine, 'websm.org', currently boasts double that amount of references: 'More than 2,000 bibliographic units are organised in the bibliographic database. The database is systematically updated from around 100 different sources. Typically, some 80 units are added each month. ${ }^{7}$ A keyword search on this website using the term 'sport' found thirty-one published articles, but no results appeared for the term 'soccer' and only one result appeared when the keyword 'football' was used. Although this website may not be comprehensive, the lack of sources gleaned from the keyword searches acts to highlight the dearth of research on sport and specifically on football which makes use of online survey methodology.

Although there are a handful of studies that focus on the ways in which football fans use the Internet to interact with one another, the lack of research on this topic has been noted by Gibbons and Dixon who argue, with reference to the work of Garry Crawford, that the creation of rigid distinctions between fans who use the Internet and fans who do not have been partly to blame. ${ }^{8}$ Following a review of literature concerning the use of the Internet to conduct surveys, it is argued in the current paper that the use of web survey methodology is particularly useful for gathering the opinions of fans who interact within Internet-based forums (or message boards) designed specifically for football fans to discuss football-related issues. Whilst charting the course of a research project based on gathering the opinions of football fans on the relationship between English national identity and football conducted during the 2008 European Football Championships (Euro 2008), methodological strategies that were adopted and critical issues that arose regarding the dissemination of e-surveys is discussed. Rather than discussing the findings of the survey itself, the aim is to highlight the lessons learned from the research and offer suggestions for researchers adopting similar methodologies in future.

\section{E-Surveys and online communities}


Pioneering research into the use of the Internet as a means to conduct surveys/questionnaires has been produced, predominantly, by academics in marketing (particularly that relating to e-commerce), psychology and various medical professions. Their discussion of e-surveys has centred, in particular, on the ability of the researcher to convert traditional paper-and-pencil surveys into electronic versions to be distributed via email, rather than by the widely accepted postal or face to face methods researchers have become accustomed to. ${ }^{9}$ Comparisons of email distribution with traditional postal and fax methods were often conducted in order to assess the suitability of the Internet as a means of acquiring respondents and to analyse the validity of data derived from e-surveys. The comparisons also illustrated many of the key logistical advantages e-surveys have over their traditional counterparts, which include a significant reduction in the time and financial resources devoted to research; ${ }^{10}$ an increase in the speed and efficiency of data handling $;{ }^{11}$ increased anonymity of respondents for web-based surveys ${ }^{12}$ and, the number of respondents a researcher can deal with at any one time. ${ }^{13}$ Although there is no consensus on the subject, researchers have also reported an increased response rate to e-surveys when compared to traditional means. ${ }^{14}$ Problems with using esurveys, either encountered or anticipated, include those created by technological issues; ${ }^{15}$ the unrepresentative nature of Internet users $;^{16}$ the need for researchers and participants to have technical expertise $;{ }^{17}$ and, bias resulting from the inflated number of self-selecting respondents. ${ }^{18}$

Some recent studies have attempted to move away from the direct conversion of paper-andpencil surveys in order to take advantage of the multimedia and programming possibilities the World Wide Web has to offer. Even so, the desire to exercise control over the sample of respondents has caused even the most innovative researchers to resort to the use of email, as a direct replacement of the letter or facsimile for distributing surveys. ${ }^{19}$ Other studies have been bolder in attempting to utilise the research possibilities of the Internet and have used online communities and their accompanying message boards, or newsgroups, as a means to recruit respondents for their surveys. ${ }^{20}$ The comparative ease with which respondents can be gathered and the attraction of large numbers of completed surveys are apparent, yet Buchanan and Smith's personality testing of newsgroup members is disappointing due to the absence of any in-depth consideration of the chosen method; the way respondents were recruited, the motivations behind the use of the method, the benefits and difficulties 
experienced and the consequences of such an approach. ${ }^{21}$ Likewise, whilst Parkinson and Evans clearly convey the direct contact they had made with twelve online communities, and explain that they had recruited respondents by posting a link to their survey on the message boards of these communities; their deliberation ends there and lacks any detailed assessment of the merits of such an approach. $^{22}$

Elsewhere, online discussion forums/message board communities have received an increasing amount of academic attention. ${ }^{23}$ The ethics of using such communities for research has been discussed at length, ${ }^{24}$ and the complex social relationships and other dynamics evident within online communities have also been analysed. ${ }^{25}$ There is a notable absence, however, of discussion regarding the use of online message board communities to disseminate e-surveys, despite Schmidt and Nosek et al's fleetingly acknowledgement of the potential of message boards as a distribution channel. ${ }^{26}$ Eysenbach and Wyatt go slightly further by arguing that the self-selection of respondents for 'open' esurveys is a source of bias. They contend that self-selection bias comes from the fact that people are more likely to respond to questionnaires if they see items that are of interest to them and also because data is less valid than if the researcher had targeted a respondent sample more directly. ${ }^{27}$

Eysenbach and Wyatt's argument neglects the fact that even with samples of 'invited' respondents a self-selection bias is still evident, albeit one which can be analysed more thoroughly. It also negates the fact that many discussion forums are for 'members only', thus making them a specific body of potential respondents, rather than an entirely open one. Despite this, Eysenbach and Wyatt are amongst a small minority who have commented in any depth on the distribution of surveys via alternative means. The current paper will hopefully go some way to filling that substantial void by critically assessing the use of message boards to disseminate e-surveys via a case study, and the effectiveness of this method for acquiring data regarding football fandom. In the following section the specific procedures used for creating and disseminating an e-survey within a specific online community for football fans are discussed. ${ }^{28}$

\section{Creation and distribution of an e-survey within a specific online community for football fans}


The vast majority of football clubs have created fan discussion forums on their websites, as have many governing bodies and associations related to football. There are also a plethora of 'unofficial' sites, many of which are not formally linked to any club, governing body or association. ${ }^{29}$ The online community within which this study was conducted could be regarded in this way and was chosen specifically because of its independence from any single club, governing body or association. The online community is an independent site created, maintained and for the use of football fans from all over the globe. The site was established in 2007 and remains active at the time of writing with well over one thousand members - a figure that continues to grow.

For the purposes of collecting the opinions of English fans on the relationship between English national identity and English football, an online questionnaire was designed for distribution in the online community. The survey contained a mixture of multiple-choice and open-response items. Response option formats included plain-text typed entry, radio buttons and pull-down menus. These were dependent on whether questions were open or closed and on limitations placed on the options provided.

The questionnaire was distributed prior to the Euro 2008 tournament, for which England (as well as all the other home nations within the UK) failed to qualify. The e-survey was live for a twelve month period from $2^{\text {nd }}$ May 2008 and the total number of completed questionnaires from respondents who fulfilled the inclusion criteria was 127 . Prior to this, a short pilot study was conducted with fifteen Teesside university staff members which enabled the author to ensure that the following four key considerations suggested by Best and Krueger were taken into account: uniformity, usability, security and anonymity. ${ }^{30}$ The questionnaire was designed to be as uniformly accessible to potential participants as possible. Standardised online survey software was used to create the survey which appeared in an identical format on whatever platform the user was reading it on. ${ }^{31}$ No images were included in order to ensure downloading of the survey pages was as swift as possible, which meant participants did not lose interest in completing the survey between pages. Thus through ensuring uniformity in these ways completion rates were optimised. The use of standardised survey software also ensured that the questionnaire had a high level of usability in that it was easy and quick for users 
to complete. Similar questions were grouped together to ensure one led onto the next and maintained the respondents' interest. Demographic information such as age, gender, nationality, ethnicity and occupation/annual earnings were left until the end so that respondents got the opportunity to provide their opinions on aspects relating to their own football fandom practices straight away. This again helped towards ensuring blank answers were kept to a minimum.

The survey software used to create the questionnaires also ensured security was maintained as multiple submissions from the same respondent were guarded against because access to the survey was blocked from any specific computer once it had been used to complete the questionnaire. There is a small chance that respondents logged into another computer to submit the questionnaire multiple times, but there was little way of controlling this and all individual responses were checked for duplication of answers also. Although the link to the survey could have fallen into the hands of people outside of the intended sample frame - as it was possible for it to be copied and sent via email - all that mattered was that respondents were English football fans. If respondents forwarded the survey link onto third parties who themselves completed the survey, then it was highly unlikely that they were not also English fans. In any case, only respondents who fulfilled the inclusion criteria were included in the data set to be analysed. ${ }^{32}$ Murthy actually regards the fact that online survey links can be passed on to others by respondents as beneficial because 'the benefit of e-questionnaires is that respondents frequently e-mail friends, co-workers, and relatives asking them to also participate in the research. ${ }^{, 33}$

\section{Entrée to the field, membership and rapport}

The first author maintained involvement in the online forum over a sustained period totalling fourteen months and was thus involved in interacting with members of the community often on a daily basis. Therefore the type of observation conducted here embodies the most involved of the three ways of conducting observation-based research outlined by Angrosino, 
participant observation, grounded in the establishment of considerable rapport between the researcher and the host community and requiring the long-term immersion of the researcher in the everyday life of that community. ${ }^{34}$

Referring to the membership roles developed by Adler and Adler, the author was an 'active' member researcher in the online fan community. Active member researchers are,

those who become involved with the central activities of the group, sometimes even assuming responsibilities that advance the group without necessarily fully committing themselves to members' values and goals. ${ }^{35}$

According to Murthy, 'the role of observer can still sometimes be considered 'passive' in the eyes of...chat room users if the researcher is not overtly interacting with them. ${ }^{36}$ This was certainly not the case with the study employed here. The author became a member of the online forum in question and actively contributed through posting new discussion topics as well as joining in existing discussion threads started by other users. Therefore the author was an 'active' rather than a 'passive' participant in terms of his engagement within the research participants.

The author joined the online community on 12 June 2008 and went on to make 204 posts, the final one being 12 September 2009. Having already secured permission to join the forum for research purposes from the founder via email prior to formally joining (see ethical considerations section below), steps were taken to ensure members were explicitly aware of the author's presence and intentions. The author's initial post was made within the 'New Signings' area of the forum where new members were directed to in order to introduce themselves. When the author initially introduced himself in this area he used similar information to that cited in the email sent to forum moderators asking for access to the forum, including the addition of the Euro 2008 survey link. This helped to establish his authenticity as a legitimate academic researcher, and also to invite members to complete the survey:

$$
\mathrm{FC} 1:^{37}
$$


P1 June 122008 11:06am ${ }^{38}$

$1:{ }^{39} \mathrm{Hi}, \mathrm{I}$ 'm an academic researching various aspects of football fandom through asking fans their views and opinions of current issues (particularly in the English Game). Moderators - I have requested permission from (fan 3 ) in admin to post on this forum. ${ }^{40}$

Questions I will be asking will be designed to build on responses to the following online questionnaire which I'd really encourage anyone interested in the state of the English game to complete: http://www.survey.bris.ac.uk/teesside/englishclubfans 2008

Any information you give me will be anonymised and used solely for academic conference proceedings, journal articles, books and for teaching purposes. I will never ask for or record any information that might lead to forum members being identified (such as names, email addresses or IP addresses).

I look forward to talking to you about your views and opinions.

(Fan 1)

This initial post was well received by forum members, a number of whom seemed genuinely interested in the research and gave feedback on the survey itself. This acted as a kind of 'rubberstamp' so that other fans felt they could trust the researcher. This proved important in the researcher establishing 'rapport' with some key forum members (or 'gatekeepers') - an essential requirement of any ethnographic research study. ${ }^{41}$ Some of the first interactions the author had with other forums members arose in relation to this initial post:

FC1:

P3 June 122008 11:09am

3: Hello mate good luck and welcome to the forums.

P6 June 122008 11:30am

1: Many thanks (fan 3)!

P4 June 122008 11:23am

4: I'm sure you will get a lot of replies from this footie mad lot

P7 June 122008 11:31am

1: I hope so! Cheers for your support! 
P8 June 122008 01:15pm

5: welcome and hopefully this forum will help your research

P9 June 122008 02:32pm

1: Cheers (fan 5)!

P15 June 122008 03:57pm

9: Done it for you, all the best mate (Thumbs up emoticon). ${ }^{42}$ Some interesting questions there, I'd be interested in knowing your findings once you have finished your research.

P16 June 122008 05:31pm

1: Cheers (fan 9). I'll let you know the main findings as and when (Thumbs up emoticon)

FC2:

P12 June 222008 07:14pm

20: Just filled this in, interesting questions and a good bit of room to give an opinion and not just select an option.

P14 June 232008 06:39pm

1: Thanks for the feedback mate (cheers emoticon).

Within this initial discussion thread and others there were examples to highlight the author gaining rapport and acceptance amongst forum members. This usually revolved around explaining what the research was about, for instance:

FC1:

P10 June 122008 02:52pm

6: Welcome! I have completed your survey. Hope the research goes well. What exactly is it for?

P12 June 2008 03:49pm

1: Cheers (fan 6)! It's for an academic research project I am conducting on the opinions of football fans on key issues within English football at the moment. Therefore it's partly to do with finding out the 
significance of football in the lives of fans today but also to do with the link between English national identity and football. The thing is that academics often make assumptions on what fans think without actually asking them! Basically I want to change that by asking fans themselves. Your help is very much appreciated.

P23 June 24 12:08pm

7: Generally is it the concept of nationalism that you are interested in?

P24 June 242008 04:38pm

1: Yes, that's what I'm interested in specifically as well as the significance of football in people's lives.

P30 June 242008 05:53pm

7: Do you view nationalism as a negative thing in this day and age?

P32 June 252008 05:04pm

1: Not sure whether I see it as either positive or negative really - it both unites and divides people and I'm interested in the power sports like football have in reinforcing this. What are your views?

\section{P33 June 252008 05:56pm}

7: I don't see anything wrong with it up to a point. However, it's clear that politicians, corporations and the media use it as a means of controlling the masses in a divide and rule sense. For example I don't swallow all the crap like the country is being overrun by immigrants or that we must invade other countries for queen and country.

\section{P34 26 June 2008 08:54am}

1: I know what you mean re the power of the media, corporations and politicians. What part do you think football (particularly in England) plays (if any) in this though?

\section{P35 26 June 2008 12:38pm}

7: It probably helps reinforce this sense of national identity. Football gives ordinary people the chance to feel like they are part of a community, which perhaps they don't get in their daily lives. Perhaps this feeling of isolation is greater amongst English people than in other countries and therefore national pride takes on a greater importance.

Another fan in this thread wanted to ask about the author's football-related credentials which had the impact of initiating further rapport: 
P25 June 242008 04:54pm

13: Out of interest, do you support any teams? Where abouts are you from?

P26 June 242008 05:01pm

1: Well I loosely follow Gillingham FC because I'm originally from Kent. However, many of my family are from Chester so I saw a few Liverpool games when I was young and now tend to follow them too. I live in Teesside at the moment so have seen a few Boro games as well.

P27 June 242008 05:09pm

13: (Smiley face emoticon) we relegated the gills last season (Smiley face emoticon)

P31 June 252008 05:01pm

1: Thanks for reminding me of that! (Angry then smiley emoticons)

P28 June 242008 05:17pm

11: Hope you're proud of yourselves.... poor Gillingham... (Emoticon with shades)

P29 June 242008 05:47pm

13: poor gills yes, but their chairman's a prick.

Issues involved in gaining access to participants who interact with one another on the forum used for distribution of the online survey, as well as ethical considerations involved in using this kind of data, are discussed in the following section.

Access and ethical considerations in conducting online survey research in a semi-public online environment

Sveningsson contends that, "when studying online environments, it may often be too difficult to 
obtain informed consent. ${ }^{43}$ Specifically focussing on participant observations within chat rooms/discussion forums, she goes on to explain that because members log on and off rapidly, the window of opportunity for informing and gaining consent is minimal. Also she highlights that if a researcher were to post a message asking for consent every time a new member logged on, other members might get annoyed and the rapport the researcher was attempting to establish could be seriously under threat meaning the opportunity to obtain rich data could be severely compromised. Sveningsson also states that even if researchers took the time to write and send private messages to all potential participants, there would be very little time left on the part of the researcher to observe online interactions - the very point of conducting the research in the first place.

Many of Sveningsson's concerns are closely aligned with the guidelines provided by 'The Association of Internet Researchers' (AoIR). ${ }^{44}$ Although the AoIR ethics working group recommend that it is sometimes acceptable to collect data online without informed consent, providing the material is not sensitive and the online environment is public, Sveningsson urges that the variables of public/private and sensitive/not sensitive are not as unambiguous as they may seem at first glance' and therefore require further consideration in Internet based research, particularly that which is ethnographic in nature. ${ }^{45}$

Sveningsson suggests that public and private online environments cannot be simply dichotomised. Rather than simply conceiving of such online spaces as either public or private, instead Sveningsson argues that it is more accurate to consider where specific domains might exist along the following four point continuum: first, public environments, such as web pages or completely open chat rooms; second, semi-public environments, such as most web communities or social network sites; third, semi-private environments, such as companies or organisations intranets; and fourth, completely private environments, such as online photo albums or private/invite only sections of chat rooms or web communities. Considering the online fan community used within this study was a 'member-only' discussion forum and in order to become a member fans must first complete a registration form and agree to various terms and conditions of membership, it seems reasonable to class it as second along Sveningsson's continuum. The forum is a 'semi-public' environment because: 'It is in principle 
accessible to anyone, but it first requires membership and registration. ${ }^{46}$ The online community drawn upon in this research is therefore closer to the public end of the spectrum than it is to the private end.

Another important ethical consideration is whether the content of forum members' postings are sensitive or not sensitive. The content of the online community used here can be viewed freely by absolutely anyone, it is only if one wants to post that they are required to register. This ensures that anyone who makes an active decision to become a member is acutely aware that anything they post is in the public domain. This makes the possibility of members posting personally sensitive information somewhat unlikely. In addition to this, the content that the researcher was interested in using as data related to the topic of English national identity and its links to football fandom. Such a topic is what Sveningsson would regard as 'public content' because it relates to 'societal matters' - English national identity and football - rather than any aspects of individuals' private lives. ${ }^{47}$ The researcher was primarily interested in the diversity of viewpoints that exist in relation to the multi-faceted relationship between English national identity and football fandom. Therefore, the content of the data gathered in this study is regarded as ethical both in its nature and scope. However, this is by no means the case with all research topics and researchers should ensure they are acutely aware of the sensitivity of the information required in their own surveys.

Although initial access to the online community was fairly straightforward, the choice to conduct the research overtly may have impacted upon the relationships made with the participants and latterly to the content of the e-survey findings. According to Garcia et al, the 'researcher's identity can affect how conspicuous they are in the setting and the likelihood that potential informants will be willing to talk to them. ${ }^{48}$ Perhaps one of the most likely ways in which the researcher-participant relationship might have been influenced was by the administrator of the forum placing a note in the author's avatar signature (which appeared under every post he made) stating that permission had been granted to conduct the research. The alternative to the overt approach taken here would have been to infiltrate the online domain and conduct research covertly. Although this might have gleaned different data due to members being completely unaware that they were being researched, it is doubtful to have 
been ethically viable and for this reason the kind of identity deception it is easy to maintain in anonymous online settings was avoided here. ${ }^{49}$

\section{Conclusions: has the use of e-surveys been effective in accessing the views of football} fans?

Our aim throughout the paper has been to demonstrate that the use of web survey methodology is particularly useful for gathering the opinions of fans who interact within online discussion forums for football fans. The procedures alluded to in the distribution of an e-survey in this context have hopefully highlighted that an in-depth understanding of CMC between football fans and the dynamics within online communities (in which this CMC takes place), is necessary to any researcher hoping to capitalise on the potential data that can be gleaned from such a source. We shall, therefore, conclude by reflecting on the methodology adopted and offering suggestions to future researchers.

The study of specific communities via e-surveys, whether predominantly 'offline' in their orientation or specifically 'online', demands the consideration of a number of methodological issues and strategies which are, in fact, more typical of ethnographic studies than they are of traditional survey research. In particular, the research study demonstrated the importance of a well planned and executed entrée, together with the value of unearthing and communicating effectively with key gatekeepers. As is the case with ethnographic studies, if such areas are neglected or unsuccessful, the quality and quantity of responses acquired by an e-survey are likely to be compromised.

As Hammersley and Atkinson remarked, ethnographic research has a tendency to rely on 'initial access negotiations [that] may be focused on official permission that can legitimately be granted or withheld by key personnel. Although not necessarily the case, such gatekeepers are often the ethnographer's initial point of contact with such research settings. ${ }^{50}$ In order to gain access to fans and garner a positive response from them towards the e-survey, the researcher deliberately targeted 
the administrator of the forum itself. Again, Hammersley and Atkinson argue that 'knowing who has the power to open up or block access, or who consider themselves and are considered by others to have the authority to grant or refuse access, is, of course, an important aspect of sociological knowledge about the setting. ${ }^{51}$ The successful outcome of contact and negotiation with the forum administrators prior to posting the e-survey bestowed the research study with a hugely rewarding access point to the members of the online community in question.

The influence of, and respect for, specific members of the online fan community was of critical importance. Prior to a discussion 'thread' being initiated, which stated the purpose of the research and provided a web link directing fans to the survey, contact was made with an active moderator of the forum. As well as gaining permission to use the forum for research purposes, there was also an expectation that an endorsement from an important community figure would generate a favourable response to the research from the community at large. The moderator not only agreed to the use of the forum for research purposes, but responded to the discussion thread himself, actively encouraging members of the forum to take part. This was an invaluable introduction to the online community, as the e-survey was presented to its members from one of their own, a respected and regular contributor to discussion threads. Again this ensured that, to most message board users, the research project was perceived to be of value to the community at large, whilst not being regarded as an intrusion.

The need to adopt research strategies from ethnographers, when using message boards for research, was acknowledged by Millward in his study of the evolution of football fanzines. ${ }^{52}$ However, the use of online discussion forums as a means of recruiting survey participants and the necessity of adopting elements of ethnographic methodology is a subject that needs developing in greater depth so that the specific features of such research are fully considered. Our own research study highlighted some of the key advantages and disadvantages of using online forums in this way, which we shall now turn to.

First, the nature of online forum discussions means that e-surveys are not completed by respondents in complete isolation from one another. Forum threads allow potential respondents to openly discuss the research project and specific questions within the survey itself. We deliberately 
use the term 'potential' respondents, rather than 'actual', as one of the distinct advantages of disseminating e-surveys via discussion boards is that they also allow the researcher to engage with those who chose not to complete the survey. The discussion thread allowed members of the online community in question to voice their opinion on the topic, give feedback on the research project, and indicate potential reasons as to why they were unwilling to be fully fledged participants.

As typical of participant observation studies, discussion threads facilitate a level of interaction amongst respondents and also between researcher and respondents that is untypical of most traditional survey means. Few other means of survey dissemination create support and feedback mechanisms such as this, where potential respondents are able to discuss pertinent issues directly with the researcher themselves or, critically, with peers whose opinion they value and with whom they can seek clarification in solace. When one compares the use of online forums to, say, the more traditional postal survey, whilst both seek survey completions on an individual basis, message boards offer community wide support and assistance, whilst most postal surveys only offer recipients direct contact with the researcher(s). Whilst the potential is there for respondents to be misled by other forum posts, researchers who monitor their discussion threads closely and become active members of the community will be able to intervene when required, allay concerns about the survey, offer solutions to problems and address misinterpretations.

Feedback from forum users illustrated one of the key advantages of using online forums to conduct e-survey research. A number of fans suggested that completing a survey about themselves and the club they support was not a significant departure from their primary activity within the online community itself, and actually corresponded strongly with their principle motivation for joining in the first place. Whilst the boundaries of discussion had been defined more formally and directly, and whilst there was clearly less scope for interaction with others within the survey itself, many fans use discussion forums for, amongst other things, voicing their opinion and writing about the club they support and the issues surrounding it. As such, discussion forums not only allow the researcher to target a specific community or group of respondents, but they also help to increase respondent numbers by marrying the way in which the research instrument gathers data as closely to the interests 
of the target group as possible and, simultaneously, as closely to the medium through which that community articulates its interests and opinions in the first instance.

However, it must be noted that the opportunity community members have to converse about e-surveys and their content could, conceivably, distort the findings of the survey. It is important that researchers compare and contrast completed surveys and discussion threads in order to assess the impact they may have had upon one another. By openly discussing the content of the e-survey and offering personal responses in a public forum, community members have the potential to influence the viewpoints and, therefore, the survey answers, given by future respondents. As Morgan noted, with regard to focus groups, it is possible to detect an inclination 'toward conformity, in which some participants withhold things that they might say in private, and a tendency toward "polarization", in which some participants express more extreme views in a group than in private' ${ }^{53}$ The opposite is also as likely, that an 'extreme' viewpoint, which goes against the grain of community opinion, is tempered as a result of forum discussions. In addition, conformity and polarization might also occur amongst message board users when influential, dominant or 'expert' community members articulate the acceptable or pseudo-official response to research questions. Participants may conform to the opinions of certain community members which could, in turn, lead to the narrowing and polarization of responses.

Overall, the research project highlights the value of establishing connections with key gatekeepers in order to gain greater levels of acceptance from research participants, which in turn maximises the quality and quantity of completed surveys. With regards to online discussion forum communities for football fans specifically, the importance of planning the researcher's entrée into the community under study and the understanding of existing relationships between forum users is critical. Future research into online football fan communities would benefit greatly by devoting attention to the formative stages of research, perhaps contributing to the community and establishing relationships with its members prior to and after the dissemination of the e-survey itself.

\section{Notes}




\footnotetext{
${ }^{1}$ The term 'football' is used instead of 'soccer' throughout this article to refer to the sport of Association football.

${ }^{2}$ Buchanan and Smith, 'Using the Internet for Psychological Research'.

${ }^{3}$ Katz, Rice and Aspden, 'The Internet, 1995-2000: access, civic involvement and social interaction'.

${ }^{4}$ Lee, Fielding and Blank, 'The Internet as a Research Medium: An Editorial Introduction to The Sage Handbook of Online Research Methods'

${ }^{5}$ Hine, 'Virtual Methods and the Sociology of Cyber-Social-Scientific Knowledge'.

${ }^{6}$ Ibid., 3.

${ }^{7}$ WebSM.org. 'Bibliography'. Web Survey Methodology. http://www.websm.org/c/85/Bibliography/?preid=0 (Accessed Aug. 2010).

${ }^{8}$ Crawford, Consuming Sport: Fans, Sport and Culture; Gibbons and Dixon, 'Surf's Up! : A call to take English soccer fan interactions on the Internet more seriously'.

${ }^{9}$ Buchanan and Smith, 'Using the Internet for Psychological Research'; Cobanoglu, Warde and Moreo, 'A comparison of mail, fax, and web-based survey methods'; Jones and Pitt, 'Health surveys in the workplace: comparison of postal, email and World Wide Web methods'; Kaplowitz, Hadlock and Levine, 'A comparison of web and mail survey response rates'; Schleyer and Forrest, 'Methods for the design and administration of webbased Surveys'; Zhang, 'Using the Internet for survey research: a case study'.

${ }^{10}$ Schleyer and Forrest, 'Methods for the design and administration of web-based Surveys'.

${ }^{11}$ Cobanoglu, Warde and Moreo, 'A comparison of mail, fax, and web-based survey methods'.

${ }^{12}$ Markham, 'Internet communication as a tool for qualitative research'.

${ }^{13}$ Schmidt, 'World-Wide Web survey research: benefits, potential problems, and solutions'.

${ }^{14}$ Kaplowitz, Hadlock and Levine, 'A comparison of web and mail survey response rates'.

${ }^{15}$ Schmidt, 'World-Wide Web survey research: benefits, potential problems, and solutions'.

${ }^{16}$ Buchanan and Smith, 'Using the Internet for Psychological Research'.

${ }^{17}$ Tingling, Parent and Wade, 'Extending the capabilities of Internet-based research: lessons from the field'.

${ }^{18}$ Zhang, 'Using the Internet for survey research: a case study'.

${ }^{19}$ Tingling, Parent and Wade, 'Extending the capabilities of Internet-based research: lessons from the field'.

${ }^{20}$ Buchanan and Smith, 'Using the Internet for Psychological Research'; Parkinson and Evans, 'Anabolic androgenic steroids: a survey of 500 users'.

${ }^{21}$ Buchanan and Smith, 'Using the Internet for Psychological Research'.

${ }^{22}$ Parkinson and Evans, 'Anabolic androgenic steroids: a survey of 500 users'.

${ }^{23}$ The terms 'online discussion forums' and 'online message boards' as well as the terms 'forums', 'discussion forums', 'message boards' and 'discussion boards' are used interchangeably throughout this paper to refer to communities that exist online to discuss common interests. They usually require members to register in order to contribute in the form of posting messages or starting discussion threads. For more on the various terms used online see http://www.webopedia.com/ (Accessed Aug. 2011).

${ }^{24}$ Berry, 'Internet research: privacy, ethics and alienation: an open source approach'; Eysenbach and Till, 'Ethical issues in qualitative research on internet communities'; Kozinets, 'The field behind the screen: using netnography for marketing research in online communities'; Nosek, Banaji and Greenwald, 'E-research: ethics, security, design, and control in psychological research on the Internet'.

${ }^{25}$ Blanchard and Markus, 'The experienced sense of a virtual community: characteristics and processes'; Chu, 'A study of members' helping behaviours in online community [sic]'; Porter, 'A typology of virtual communities: a multi-disciplinary foundation for future research'.

${ }^{26}$ Schmidt, 'World-Wide Web survey research: benefits, potential problems, and solutions'; Nosek, Banaji and Greenwald, 'E-research: ethics, security, design, and control in psychological research on the Internet'.

${ }^{27}$ Eysenbach and Wyatt, 'Using the Internet for surveys and health research'.

${ }^{28}$ Specific details of the forum in question have been omitted in order to protect the identity of its members.

${ }^{29}$ See for example Kennedy and Kennedy, 'It's the little details that make up our identity': Everton supporters and their stadium ballot debate.'

${ }^{30}$ Best and Kruger, 'Internet Survey Design'.

31 'Bristol Online Surveys' software was used to create the survey. http://www.survey.bris.ac.uk/ (Accessed Nov. 2010).

${ }^{32}$ Inclusion criteria were that respondents had to be fans of an English club and/or the English national team and they had to have an English based nationality. Those who did not fulfil these criteria, or those who had not completed over half of the questionnaire, were removed from the data set entirely.

${ }^{33}$ Murthy, 'Digital Ethnography: An examination of the use of new technologies for social research', 842.

${ }^{34}$ Angrosino, 'Recontextualizing Observation: Ethnography, pedagogy, and the prospects for a progressive political agenda', 732 .

${ }^{35}$ Cited in Ibid., 733.
} 


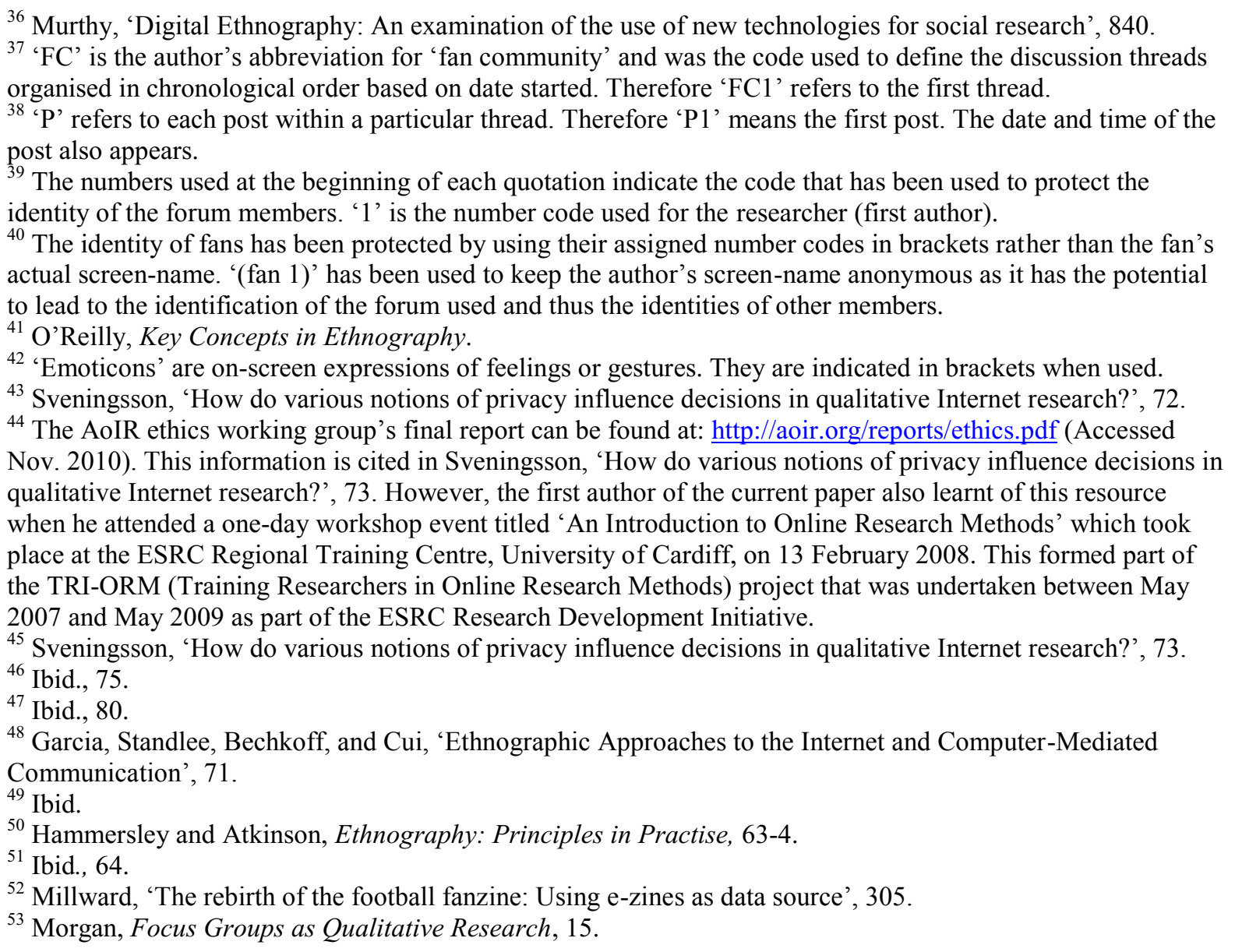

\section{References}

Angrosino, M. V. 'Recontextualizing Observation: Ethnography, pedagogy, and the prospects for a progressive political agenda'. In The Sage Handbook of Qualitative Research (Third Edition), edited by N. K. Denzin \& Y. S. Lincoln, 729-745. London, Sage, 2005.

Best, S. J. and Krueger, B. S. 'Internet Survey Design'. In The Sage Handbook of Online Research Methods, edited by N. Fielding, R. M. Lee and G. Blank, 217-235. London, Sage, 2008.

Berry, D. M. 'Internet research: privacy, ethics and alienation: an open source approach'. Internet Research, 14, no.4 (2004): 323-332.

Blanchard, A. L. and Markus, M. L. 'The experienced sense of a virtual community: characteristics and processes'. The Data Base for Advanced Information Systems, 35, no.1 (2004): 65-79. 
Buchanan, T. and Smith, J. L. 'Using the Internet for Psychological Research'. British Journal of Psychology 90, no.1 (1999): 125-144.

Chu, K. M. 'A study of members' helping behaviours in online community [sic]'. Internet Research, 19, no.3 (2009): 279-292.

Cobanoglu, C., Warde, B. and Moreo, P. J. 'A comparison of mail, fax, and web-based survey methods'. International Journal of Market Research, 43, no.4 (2001): 405-410.

Crawford, G. Consuming Sport: Fans, Sport and Culture. London: Routledge, 2004.

Eysenbach, G. and Till, J. E. 'Ethical issues in qualitative research on internet communities'. British Medical Journal, 323, no.20 (2001): 1103-1105.

Eysenbach, G. and Wyatt, J. 'Using the Internet for surveys and health research'. Journal of Medical Internet Research, 4, no.2 (2002): 00-00.

Garcia, A.C., Standlee, A. I., Bechkoff, J. and Cui, Y. 'Ethnographic Approaches to the Internet and Computer-Mediated Communication'. Journal of Contemporary Ethnography 38, no.1 (2009): 52-84.

Gibbons, T. and Dixon, K. 'Surf's Up! : A call to take English soccer fan interactions on the Internet more seriously'. Soccer and Society 11, no. 5 (2010): 599-613.

Hammersley, M. \& Atkinson, P. Ethnography: Principles in Practise. $2^{\text {nd }}$ Ed. London: Routledge, 1995.

Hine, C. 'Virtual Methods and the Sociology of Cyber-Social-Scientific Knowledge'. In Virtual Methods: Issues in Social Research on the Internet, edited by C. Hine, 1-13. Oxford: Berg, 2005.

Jones, R. and Pitt, N. 'Health surveys in the workplace: comparison of postal, email and World Wide Web methods'. Occupational Medicine, 49, no. 8 (1999): 556-558.

Kaplowitz, M. D., Hadlock, T. D. and Levine, R. 'A comparison of web and mail survey response rates'. Public Opinion Quarterly, 68, no.1 (2004): 94-101.

Katz, J.E., Rice, R.E. and Aspden, P. 'The Internet, 1995-2000: access, civic involvement and social interaction'. American Behavioral Scientist, 45, no. 3 (2001): 404-418. 
Kennedy, P. And Kennedy, D. “'It's the little details that make up our identity': Everton supporters and their stadium ballot debate'. Soccer \& Society, 11, no. 5 (2010): 553-572.

Kozinets, R. V. 'The field behind the screen: using netnography for marketing research in online communities'. Journal of Marketing Research, 39, no.1 (2002): 61-72.

Lee, R. M., Fielding, N. and Blank, G. 'The Internet as a Research Medium: An Editorial Introduction to The Sage Handbook of Online Research Methods'. In The Sage Handbook of Online Research Methods, edited by R. M. Lee, N. Fielding and G. Blank, 3-20. London: Sage, 2008. Markham, A. N., 'Internet communication as a tool for qualitative research'. In Qualitative Research: Theory, Method and Practise, edited by D. Silverman, 95-124. London: Sage, 2004.

Millward, P. 'The rebirth of the football fanzine: Using E-zines as data source'. Journal of Sport and Social Issues, 32, no.3 (2008): 299-310

Morgan, D. L. Focus Groups as Qualitative Research. $2^{\text {nd }}$ Ed. London: Sage, 1997.

Murthy, D. 'Digital Ethnography: An examination of the use of new technologies for social research'. Sociology, 42, no. 5 (2008): 837-855.

Nosek, B. A., Banaji, M. R. and Greenwald, A. G. 'E-research: ethics, security, design, and control in psychological research on the Internet'. Journal of Social Issues, 58, no.1 (2002): 161-176.

O’Reilly, K. Key Concepts in Ethnography. London: Sage, 2009.

Parkinson, A. B. and Evans, N. A. 'Anabolic androgenic steroids: a survey of 500 users'. Medicine \& Science in Sports and Exercise, 38, no.4 (2006): 644-651.

Porter, C. E. 'A typology of virtual communities: a multi-disciplinary foundation for future research'. Journal of Computer-Mediated Communication, 10, no.1 (2006): 00-00

Schleyer, T. K. L. and Forrest, J. L. 'Methods for the design and administration of web-based Surveys'. Journal of the American Medical Informatics Association, 7, no.4 (2000): 416-425. Schmidt, W. C. 'World-Wide Web survey research: benefits, potential problems, and solutions'. Behavioural Research Methods, Instruments and Computers, 29, no.2 (1997): 274-279. 
Sveningsson, M. 'How do various notions of privacy influence decisions in qualitative Internet research?' In Internet Inquiry: Conversations about Method, edited by A. N. Markham and N. K. Baym, 69-87. London, Sage: 2009.

Tingling, P., Parent, M. and Wade, M. 'Extending the capabilities of Internet-based research: lessons from the field'. Internet Research, 13, no.3 (2003): 223-23.

WebSM.org. 'Bibliography'. Web Survey Methodology. http://www.websm.org/c/85/Bibliography/?preid=0 (Accessed July 2010).

Zhang, Y. 'Using the Internet for survey research: a case study'. Journal of the American Society for Information Science, 51, no. 1 (1999): 57-68. 